\title{
Clinical study of cardiac diseases during pregnancy
}

\author{
Amitha Vijay Kamat*, Swetha Dama
}

Department of Obstetrics \& Gynaecology, Karnataka Institute of Medical Sciences, Hubli, Karnataka, India

Received: 21 January 2016

Accepted: 15 February 2016

*Correspondence:

Dr. Amitha Vijay Kamat,

E-mail: amithakamat@gmail.com

Copyright: ( ) the author(s), publisher and licensee Medip Academy. This is an open-access article distributed under the terms of the Creative Commons Attribution Non-Commercial License, which permits unrestricted non-commercial use, distribution, and reproduction in any medium, provided the original work is properly cited.

\section{ABSTRACT}

Background: Objective of the study was to evaluate the burden of cardiac diseases in pregnancy in our hospital, their clinical presentation, type of cardiac lesion, complications, maternal and neonatal outcome.

Methods: A prospective analysis conducted at Karnataka Institute of Medical Sciences, Hubli, a tertiary care center in Karnataka, between July 2014 to June 2015. All patients with cardiac diseases during pregnancy and developed during postpartum period were included in the study. Age, parity, mode of delivery, perinatal outcome, complications intra-partum and post-partum were analyzed in detail.

Results: 35 cases with cardiac disease in pregnancy were noted. Valvular heart disease accounted for 18 cases (51.4\%), acyanotic CHD were $11(31.4 \%)$, cyanotic CHD were 2 (5.7\%). 2 developed peripartum cardiomyopathy during their post natal period $(5.7 \%), 2$ were admitted with previous history of peripartum cardiomyopathy. Most common lesion noted was mitral stenosis (40.5\%). 26 had term deliveries and 7 had preterm. One maternal mortality was noted $(2.8 \%)$.

Conclusions: Cardiac diseases in pregnancy constitute high risk pregnancy and require special attention during antepartum, intrapartum and postpartum period. Rheumatic heart disease was the major contribution of cardiac diseases in pregnancy and is seen to be associated with increased maternal morbidity.

Keywords: Peripartum cardiomyopathy, Rheumatic heart disease

\section{INTRODUCTION}

Pregnancy contributes to significant hemodynamic changes i.e. $30-50 \%$ increase in cardiac output and blood volume which, in turn could lead to clinical decompensation in cardiac patients. Cardiac disease complicates about $1 \%$ of pregnancies in women. ${ }^{1-4}$ The most important causes of heart disease are rheumatic heart disease and congenital abnormalities. The proportion of women of child-bearing age with congenital heart defects, surgically treated or otherwise has increased substantially in recent decades due to improved surgical and cardiac care. ${ }^{4,5}$ However, in developing countries quite a large number of women become pregnant without seeking therapeutic intervention for cardiac lesions and many of them are only diagnosed with heart disease during pregnancy. ${ }^{1}$ In India, $90 \%$ of all cardiac disorders in pregnancy are of rheumatic origin and major cause of maternal mortality and morbidity. Worldwide, mitral stenosis is the most common valve defect responsible for maternal deaths with cardiac causes.

\section{Objectives of the study}

- To evaluate the burden of cardiac diseases in pregnancy.

- To study their clinical presentation.

- To study the distribution of different types of cardiac lesions.

- To record the complications and maternal, neonatal outcome. 


\section{METHODS}

The study was carried out in a tertiary care centre in Karnataka Institute of Medical Sciences, Hubli, over a period of one year i.e. July 2014-June 2015. All antenatal patients having cardiac disease, either previously diagnosed or during antenatal visit, patients who developed cardiac complications during peripartum period were included in the study. Patients admitted in antenatal ward, labour room and ICU, with cardiac disease were included in the study. Detailed history and cardiovascular examination was performed to determine the type of lesion, whether in congestive cardiac failure, presence of complications, investigations and treatment were analysed. Patients suspected of cardiac lesions were evaluated by echocardiogram to diagnose specific cardiac lesion.

\section{RESULTS}

The numbers of patients with significant cardiac lesions during the study period were 35.16 were booked cases at KIMS and other hospitals, 19 were referred from the periphery.

Among them, 18 patients were diagnosed of valvular heart disease $(54 \%), 11$ were congenital heart disease (29.7\%), 3 were peripartum cardiomyopathy $(10.8 \%)$ and 2 patients had previous history of peripartum cardiomyopathy and one patient suffered from ischemic heart disease during post-operative period.

Table 1: Incidence of cardiac diseases in the study.

\begin{tabular}{|lll|}
\hline & Number & $\%$ \\
\hline Valvular heart disease & 18 & $54 \%$ \\
\hline Congenital heart disease & 11 & $29.7 \%$ \\
\hline Peripartum cardiomyopathy & 3 & $10.8 \%$ \\
\hline Previous h/o PCM & 2 & $5.4 \%$ \\
\hline Ischemic heart disease & 1 & $2.4 \%$ \\
\hline
\end{tabular}

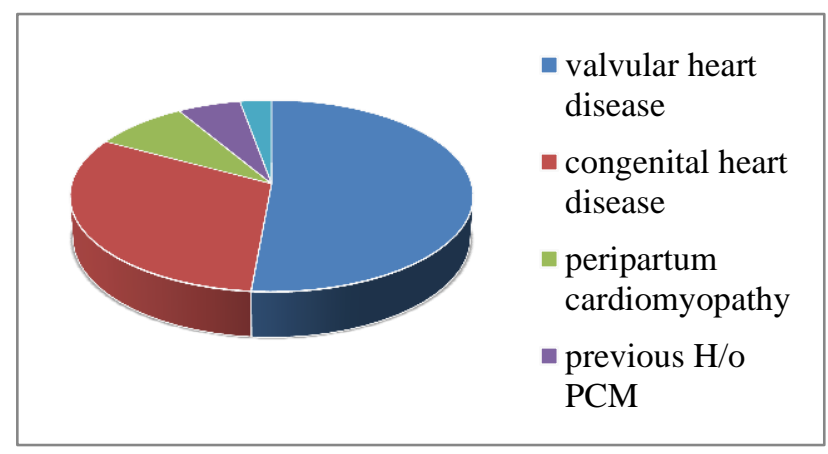

Figure 1: Incidence of cardiac diseases in the study.

Age distribution revealed that 3 patients were below $20 y$ rs of age $(10.8 \%)$, 30 patients between age group of $20-30$ years $(83.7 \%)$ and 2 were between age group of $30-40$ years $(5.4 \%)$. Parity distribution showed that 16 were primipara $(45.9 \%), 11$ of second parity $(29.7 \%), 6$ of third parity (18.9\%) and fourth parity were $2(5.4 \%)$.

Table 2: Demography.

\begin{tabular}{|lll|}
\hline \multicolumn{1}{|l|}{ Age } & Number & $\%$ \\
\hline$<20$ years & 03 & $10.8 \%$ \\
\hline 21-30years & 30 & $83.7 \%$ \\
\hline 31-40years & 2 & $5.4 \%$ \\
\hline Parity & & \\
\hline 1 & 16 & $45.9 \%$ \\
\hline 2 & 11 & $29.7 \%$ \\
\hline 3 & 6 & $18.9 \%$ \\
\hline$>3$ & 2 & $5.4 \%$ \\
\hline Mode of delivery & & \\
\hline Vaginal & 17 & $51.3 \%$ \\
\hline Caesarean & 12 & $35.1 \%$ \\
\hline Instrumental & 4 & $10.8 \%$ \\
\hline Abortion & 1 & $2.7 \%$ \\
\hline Term deliveries & 26 & $70.2 \%$ \\
\hline Preterm deliveries & 7 & $18.9 \%$ \\
\hline Pregnancy continued & 1 & $2.7 \%$ \\
\hline
\end{tabular}

17 patients delivered vaginally $(51.3 \%), 12$ by caesarean section $(35.1 \%), 3$ patients by outlet forceps delivery and 1 by ventouse $(10.8 \%)$. 1 patient had abortion at 26weeks, spontaneous. 1 patient presented with acute onset breathlessness at 29 weeks of gestation age, was evaluated and diagnosed as severe mitral stenosis and referred to higher centre for cardiac care. 25 were term deliveries ( 7 were preterm deliveries).

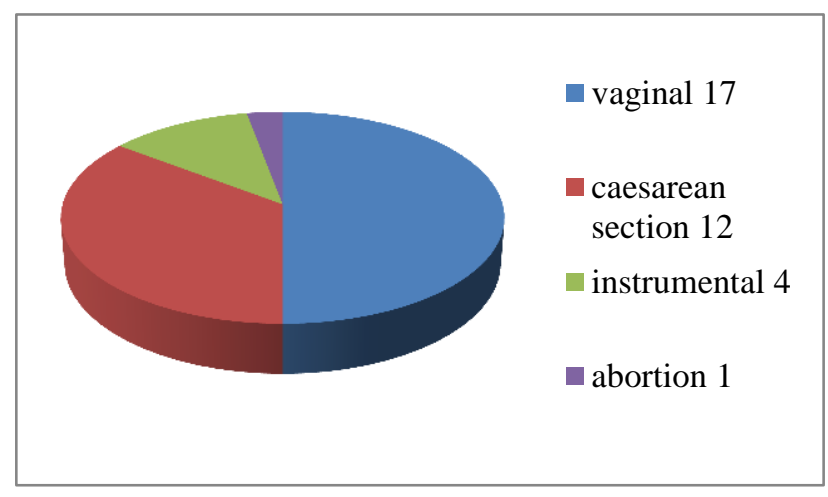

Figure 2: Mode of delivery.

Patients included in the study group were categorised based on their symptoms into NYHA classification:

NYHA class 1: 19 patients $(54.28 \%)$

NYHA class 2: 10 patients $(28.57 \%)$

NYHA class 3: 5 patients $(14.28 \%)$

NYHA class $4: 2$ patients $(5.71 \%)$ 


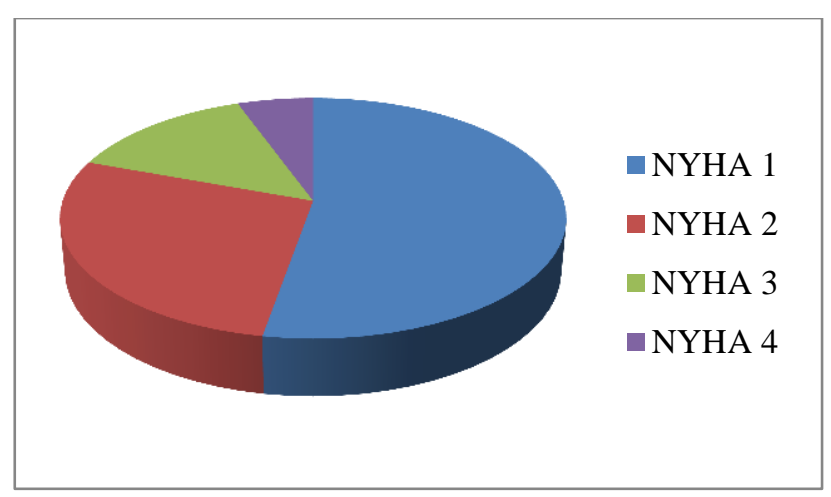

Figure 3: NYHA classification.

Patients were also classified according to WHO risk groups - Group $1-5$ patients, Group $2-8$ patients, Group 3- 12 patients and group $4-10$ patients.

Most common dominant cardiac lesion noted was mitral stenosis, noted in 15 patients $(40.5 \%)$. Other dominant lesions noted are mentioned in the table below. Associated lesions were as mentioned below.

Table 3: Dominant cardiac lesions.

\begin{tabular}{|lll|}
\hline Dominant lesions & Number & $\%$ \\
\hline Mitral stenosis & 15 & $40.5 \%$ \\
\hline Mitral regurgitation & 3 & $8.1 \%$ \\
\hline Cyanotic CHD & 2 & $5.4 \%$ \\
\hline ASD & 4 & $10.8 \%$ \\
\hline PDA & 2 & $5.4 \%$ \\
\hline PDA+ AS & 1 & $2.7 \%$ \\
\hline VSD (corrected) & 1 & $2.7 \%$ \\
\hline PS (corrected) & 1 & $2.7 \%$ \\
\hline Peripartum cardiomyopathy & 4 & $10.8 \%$ \\
\hline Previous history of PCM & 2 & $5.4 \%$ \\
\hline
\end{tabular}

Table 4: Associated cardiac lesions.

\begin{tabular}{|lll|}
\hline Associated lesions & Number & $\%$ \\
\hline Mitral regurgitation (grade I/II) & 13 & $37.1 \%$ \\
\hline Mitral valve prolapse & 2 & $5.7 \%$ \\
\hline Tricuspid regurgitation & 15 & $42.8 \%$ \\
\hline Aortic regurgitation & 5 & $14.2 \%$ \\
\hline History of repair of cardiac lesion & 8 & $22.8 \%$ \\
\hline
\end{tabular}

Two cases of cyanotic heart disease were:

1. Cyanotic heart disease with single atrium and single ventricle. Single A-V valve with pulmonary atresia. She underwent elective LSCS under graded epidural anaesthesia at 36weeks gestation age and delivered a male baby $2 \mathrm{kgs}$. Intra-op and post-op period were uneventful and the patient was discharged with a healthy baby.

2. Cyanotic CHD with Tricuspid atresia, large ASD with right to left shunt $(2.9 \mathrm{~cm}$ in size $) \&$ small VSD with Left to Right shunt and hypoplastic right ventricle. This patient presented to labour room at $33+4$ weeks gestation age with pain abdomen, on examination was graded NYHA II, was in active labour. She delivered a preterm baby of $1.3 \mathrm{kgs}$, female which survived only for a period of 5 days. Patient was discharged on postnatal day 8 with no complications and was advised routine follow-up with cardiologist.

Patients with history of repair of cardiac lesions were as follows.

Table 5: History of repair of cardiac lesions.

\begin{tabular}{|ll|}
\hline Repair of lesion & \\
\hline Corrected VSD & 1 \\
\hline Corrected ASD & 1 \\
\hline Mitral valve repair & 1 \\
\hline Percutaneous mitral valve commisurotomy & 2 \\
\hline Mitral, tricuspid and aortic valve repair & 1 \\
\hline Pulmonary stenosis( balloon valvotomy) & 1 \\
\hline ASD correction + pul valve bioprosthesis & 1 \\
\hline
\end{tabular}

Complications noted in patients during antepartum and intra-partum period.

Table 6: Complications seen during antepartum, intrapartum and postpartum period.

\begin{tabular}{|llll|}
\hline $\begin{array}{l}\text { Cardiac } \\
\text { complications }\end{array}$ & antepartum & $\begin{array}{l}\text { Intra- } \\
\text { partum }\end{array}$ & Postpartum \\
\hline $\begin{array}{l}\text { Congestive } \\
\text { cardiac failure }\end{array}$ & 1 & 2 & 2 \\
\hline $\begin{array}{l}\text { Acute } \\
\text { pulmonary } \\
\text { oedema }\end{array}$ & - & 2 & 2 \\
\hline
\end{tabular}

Table 7: Associated co-morbidities associated with cardiac disease in pregnancy.

\begin{tabular}{|ll|}
\hline Severe anaemia & 7 \\
\hline Pregnancy induced hypertension & 3 \\
\hline Lower respiratory tract infection & 1 \\
\hline Epilepsy & 1 \\
\hline Rh negative status & 2 \\
\hline History of CVA & 1 \\
\hline Hypothyroidism & 1 \\
\hline Twin pregnancy & 1 \\
\hline
\end{tabular}

Birth weight of the babies delivered by these mothers was classified as follows:

Perinatal outcome among these patients showed one baby, low birth weight, born to a mother who suffered from cyanotic heart disease, had preterm delivery at 33 weeks, $1.3 \mathrm{kgs}$, died on post natal day 5 due to respiratory distress. 
Table 8: Classification of new-borns of cardiac patient according to their birth weight.

\begin{tabular}{|ll|}
\hline Birth weight & \\
\hline$<1.5 \mathrm{kgs}$ & 1 \\
\hline $1.5-2.5 \mathrm{kgs}$ & 2 \\
\hline$\geq 2.5 \mathrm{kgs}$ & 27 \\
\hline Still born & 3 \\
\hline
\end{tabular}

\section{DISCUSSION}

Cardiac disease during pregnancy is a major risk factor for maternal and neonatal morbidity and mortality. To avoid undesirable complications during pregnancy, delivery or caesarean section, women with cardiac diseases do require special evaluations before and throughout pregnancy. This study reflects the outcome of cardiac cases during pregnancy in our hospital, which is a tertiary referral centre in Karnataka. Rheumatic heart disease was the most common cause of cardiac disease and mitral stenosis was the most common cardiac lesion noted in our study, which was comparable to other studies. $^{2,3,6-10}$

With the advent of more modern techniques and advancement in knowledge, the circulation and hemodynamic during pregnancy has been well understood and managed. ${ }^{11}$ Use of echocardiogram provides aetiology of the type of lesion and non-invasion method of ascertaining the severity of the lesion.

Certain cardiovascular diseases that make pregnancy unadvisable are (a) high grade pulmonary artery hypertension of any origin ( $\geq 50 \%$ of systemic pressure), (b) severe left or right ventricular dysfunction (LV Ejection fraction $<40 \%$ ), (c) patients with severe heart failure (NYHA class III/IV), (d) severe left heart obstruction (aortic stenosis with average pressure gradient $>50 \mathrm{~mm} \mathrm{Hg}$ according to Doppler ultrasound, high grade (recurrent) aortic isthmus stenosis, (e) severe mitral stenosis(average pressure gradient $>10 \mathrm{~mm} \mathrm{Hg}$, valve aperture area $<1 \mathrm{~cm}^{2}$ ), (f) Marfan's syndrome with ectasia of the aortic ascendans $(\geq 45 \mathrm{~mm}),(\mathrm{g})$ Cyanotic heart disease (especially with oxygen saturation $<80 \%){ }^{5}$

In the present study, the incidence of cardiac disease in our hospital is 3.5 among 1000 deliveries. Most of the patients admitted in our hospital were unbooked, referred cases from periphery and many were diagnosed of cardiac disease for the first time in index pregnancy. Women illiteracy, lack of health education, poverty, poor antenatal care, delayed referrals etc., contribute to rise in delayed diagnosis and development of complications. During our study period, one maternal mortality was contributed by a patient who suffered ischemic heart disease during post - operative period of caesarean section $(2.7 \%)$. 4 patients developed acute pulmonary oedema during or after delivery. 5 patients developed congestive cardiac failure. 2 patients had left ventricular ejection fraction $<40 \%$. These patients contribute to severe acute maternal morbidity and require careful monitoring.

\section{CONCLUSIONS}

Cardiovascular diseases in pregnancy constitute high risk pregnancy and women of child-bearing age with heart disease or cardiovascular risk factors should therefore be counselled and treated early by interdisciplinary team of gynaecologist, cardiologists and if necessary cardiac surgeons. Rheumatic heart disease remains the most common and important cause of maternal and perinatal morbidity and mortality. Pulmonary artery hypertension and myocardial dysfunction are the risk factors for maternal cardiac complications. Early detection and education, regular antenatal care and early referrals can significantly reduce the morbidity and mortality among cardiac patients.

\section{Funding: No funding sources}

Conflict of interest: None declared

Ethical approval: The study was approved by the Institutional Ethics Committee

\section{REFERENCES}

1. Sheela CN, Karanth S, Patil CB. Maternal cardiac complications in women with cardiac diseases in pregnancy. Int J Pharm Biomed Res. 2011;2(4):2615.

2. Sawhney H, Aggrawal N, Suri V, Vasishta K, Sharma Y, Grover A. Maternal and perinatal outcome in rheumatic heart disease. Int $\mathbf{J}$ Gynaecol Obstet. 2003;80:9-14.

3. Wasim $\mathrm{T}$, Amer $\mathrm{W}$, Majrroh A, Siddiq S. Fetomaternal outcome of pregnancy with cardiac disease. J Pak Med Assoc. 2008;58:175-8.

4. Davies GA, Herbert WN. Assessment and management of cardiac disease in pregnancy. J.Obstet Gynaecol Can. 2007;331-6.

5. Regitz-Zagrosek V, Seeland U, Geibel-Zehender A, Gohlke-Bärwolf C, Schaefer C. Cardiovascular diseases in pregnancy. Dtsc Arztebl Int. 2011;108(16):267-73.

6. Rossi WS, Ramires EG, Grinberg JA, Bortolotti M. Clin cardiol. 2003;26:135-42.

7. Doshi HU, Oza HV,Tekani H, Modi K. J Indian Med Assoc. 2010;108:278-80.

8. Bagde ND, Bagde MN, Shivkumar PV, Tayade S. Clinical profile and obstetric outcome in pregnancies complicated by heart disease: a five year Indian rural experience. Int J Reprod Contracept Obstet Gynecol. 2013;2:52-7.

9. Abdel Haby ES, Shamy M, El-Fifai AA. Maternal and perinatal outcome of pregnancies complicated by cardiac disease. Int J Obstet gynecol. 2005;90:21-5.

10. Bhatla N, Lal S, Behera G, Kriplani A, Mittal S. Cardiac disease in pregnancy. Int J Obstet Gynecol. 2003;26:135-42. 
11. Ghuge SH, Patil VV, Latti RG, Thorat KD. A Comparative study of cardiovascular sympathetic activity in three trimesters of pregnancy. Pravara Med Rev. 2011;3(1).
Cite this article as: Kamat AV, Dama S. Clinical study of cardiac diseases during pregnancy. Int $\mathbf{J}$ Reprod Contracept Obstet Gynecol 2016;5:855-9. 